\title{
Analysis of a Change in the Structure of Japanese Power Supply Using the using the GTAP-E-Power Model
}

Akiko Higashi ( $\square$ akiko@mri.co.jp )

Mitsubishi Research Institute, Inc.

Ken Itakura

Nagoya City University: Nagoya Shiritsu Daigaku

Yushi Inoue

Cook Research Incorporated

Hiroaki Otake

Mitsubishi Research Institute, Inc.

\section{Research}

Keywords: GTAP-E-Power model, zero-emission power supply, Japanese power structure

Posted Date: January 18th, 2021

DOI: https://doi.org/10.21203/rs.3.rs-145320/v1

License: (a) (i) This work is licensed under a Creative Commons Attribution 4.0 International License. Read Full License 


\section{Abstract}

This study analyzes the effect of a change in the structure of Japanese power supply, which disaggregates the power sector based on the GTAP-E model framework. We also discuss the update of the GTAP-E-Power model database from GTAP 9.0 to GTAP 10.0. The study further analyzes the impact of a change in the power structure on Japan's macro-economy, the power sector, and industry by comparing the results of four scenarios. In our simulations, which are divided into two periods, shocks are introduced to the growth rate in real GDP, the labor force, the population, and Japanese zero-emission power supply. First, simulations from 2014 to 2018 are performed to update the GTAP-E-Power database. Next, simulations from 2019 to 2030 are performed for policy scenarios with different growth rates of zero-emission power supply in Japan.

The simulation results show that with the same growth rate of zero-emission power supply as the Sustainable Development Scenario of the World Energy Outlook 2019, the share of zero-emission power supply in Japan in 2030 will be close to the government's target. The simulation results show that an increase in zero-emission power supply would have a positive effect on the Japanese economy.

\section{Full Text}

This preprint is available for download as a PDF.

\section{Figures}

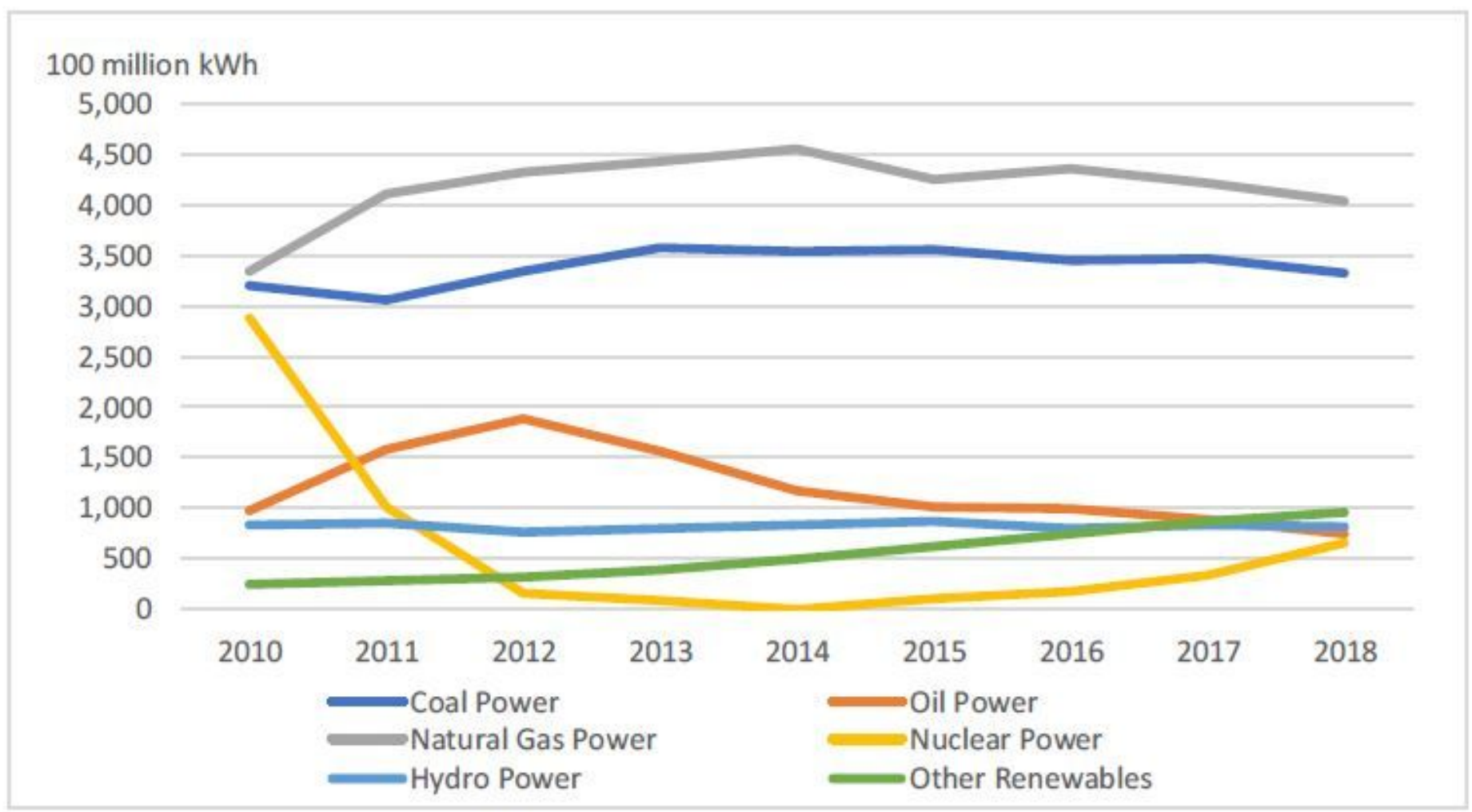


Figure 1

Total power generated in Japan from 2010 to 2018 (fiscal year, 100 million kWh区

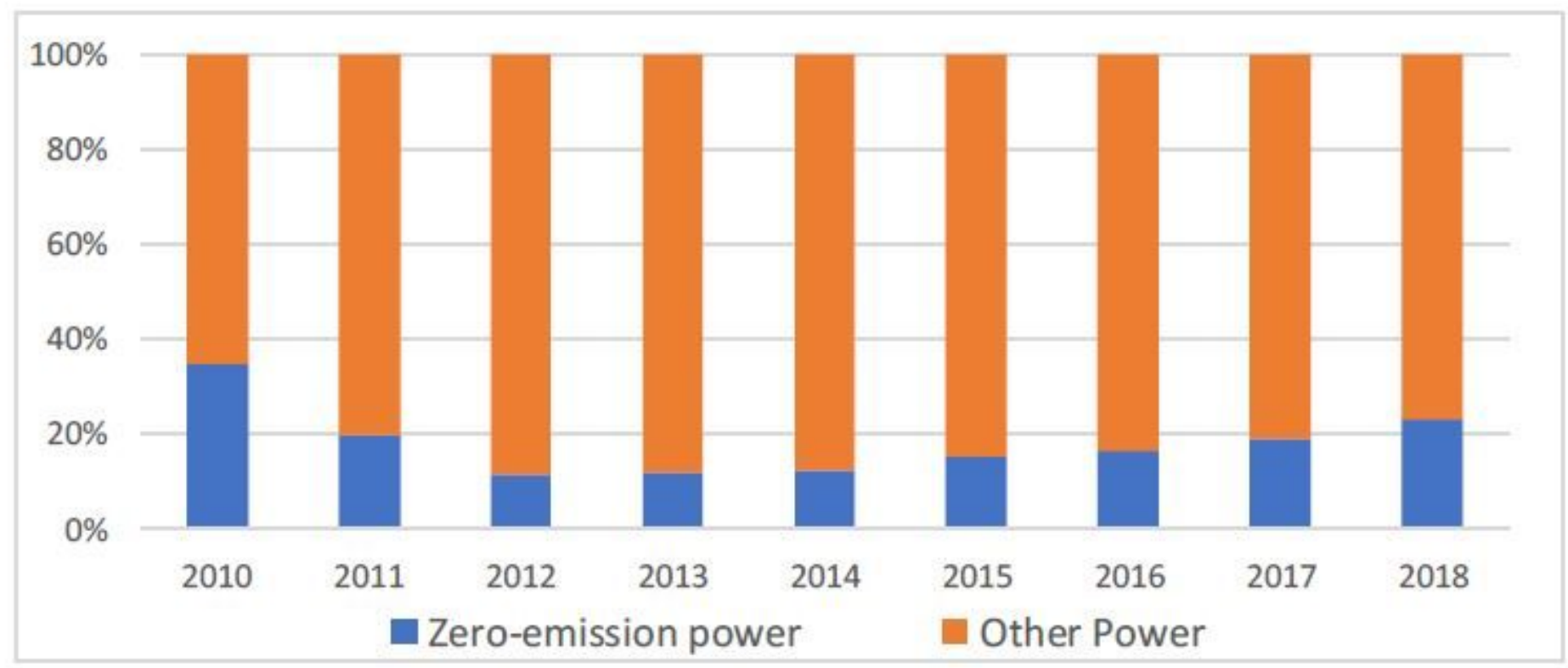

Figure 2

Share of zero-emission power in Japan from 2010 to 2018 (fiscal year, percentage『

Output
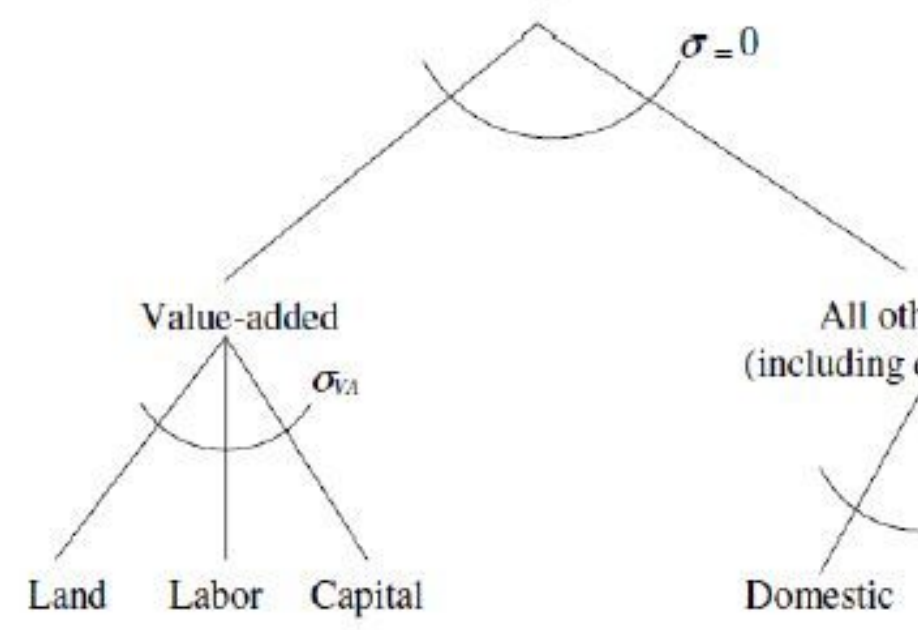

All other inputs

(including energy inputs)

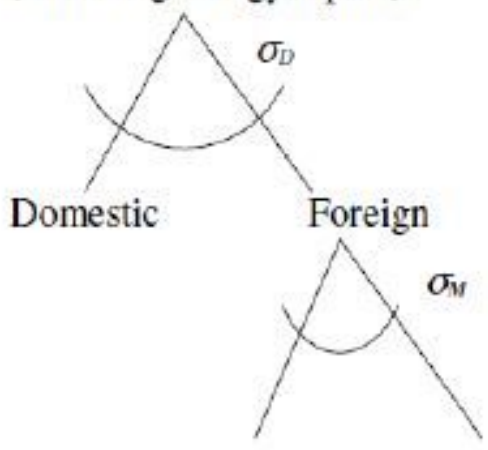

Region $1 \quad \ldots \quad$ Region $r$

\section{Figure 3}

Standard GTAP production structure Source: Burniaux and Truong (2002, Figure 15, p. 30). 


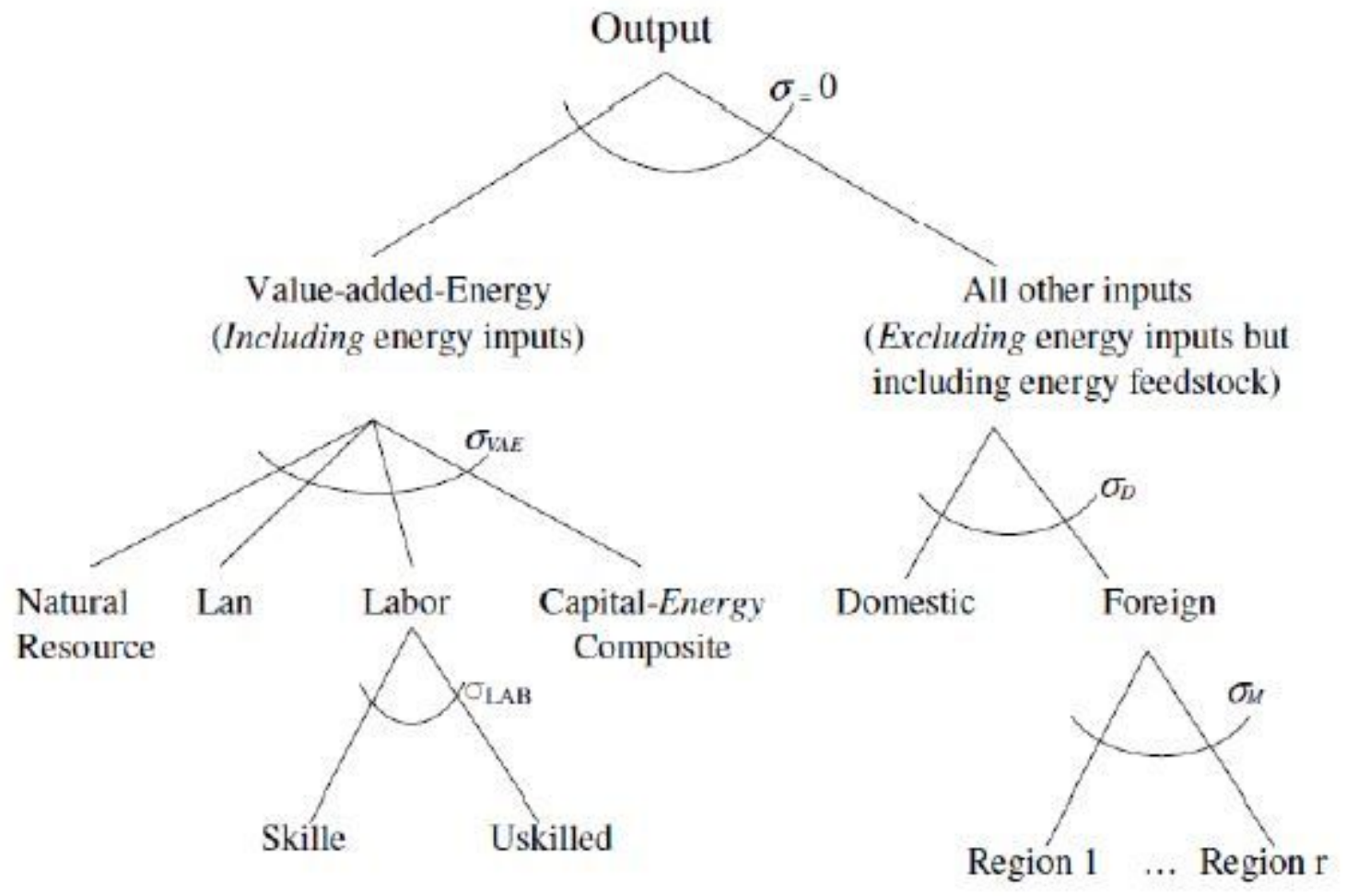

\section{Figure 4}

GTAP-E production structure Source: Burniaux and Truong (2002, Figure 16, p. 31). 


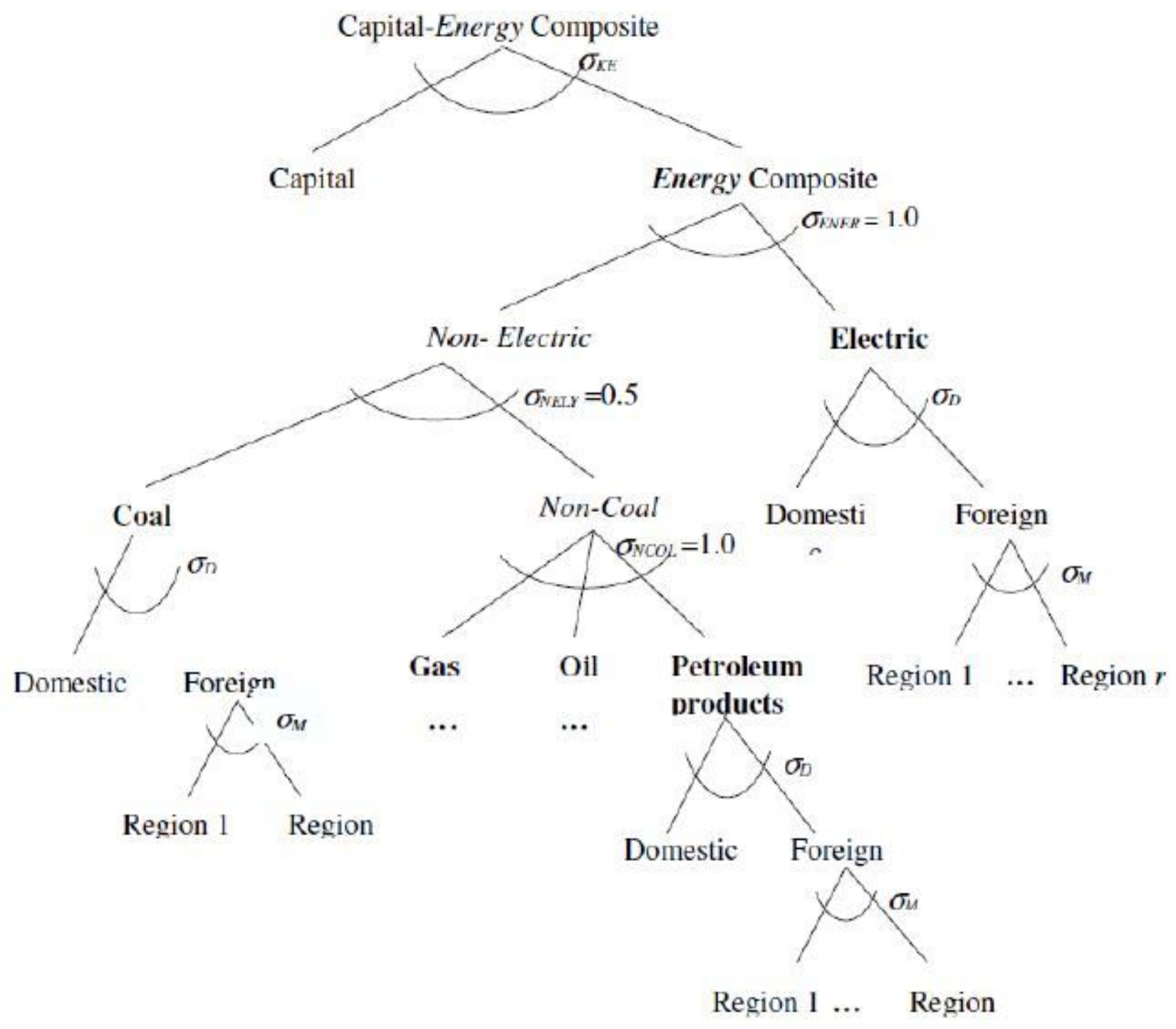

Figure 5

GTAP E capital energy composite structure Source: Burniaux and Truong (2002, Figure 17, p. 31).

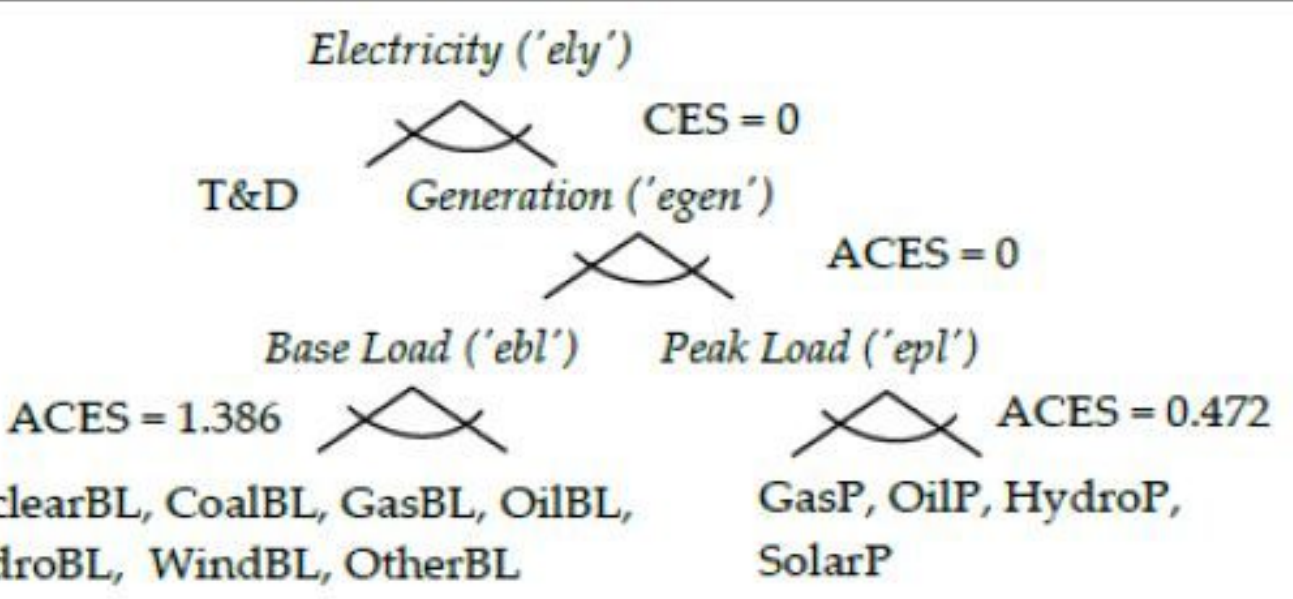

HydroBL, WindBL, OtherBL SolarP 
Nested electric power substitution in GTAP E Power Source: Peters (2016b , Figure 2, p.

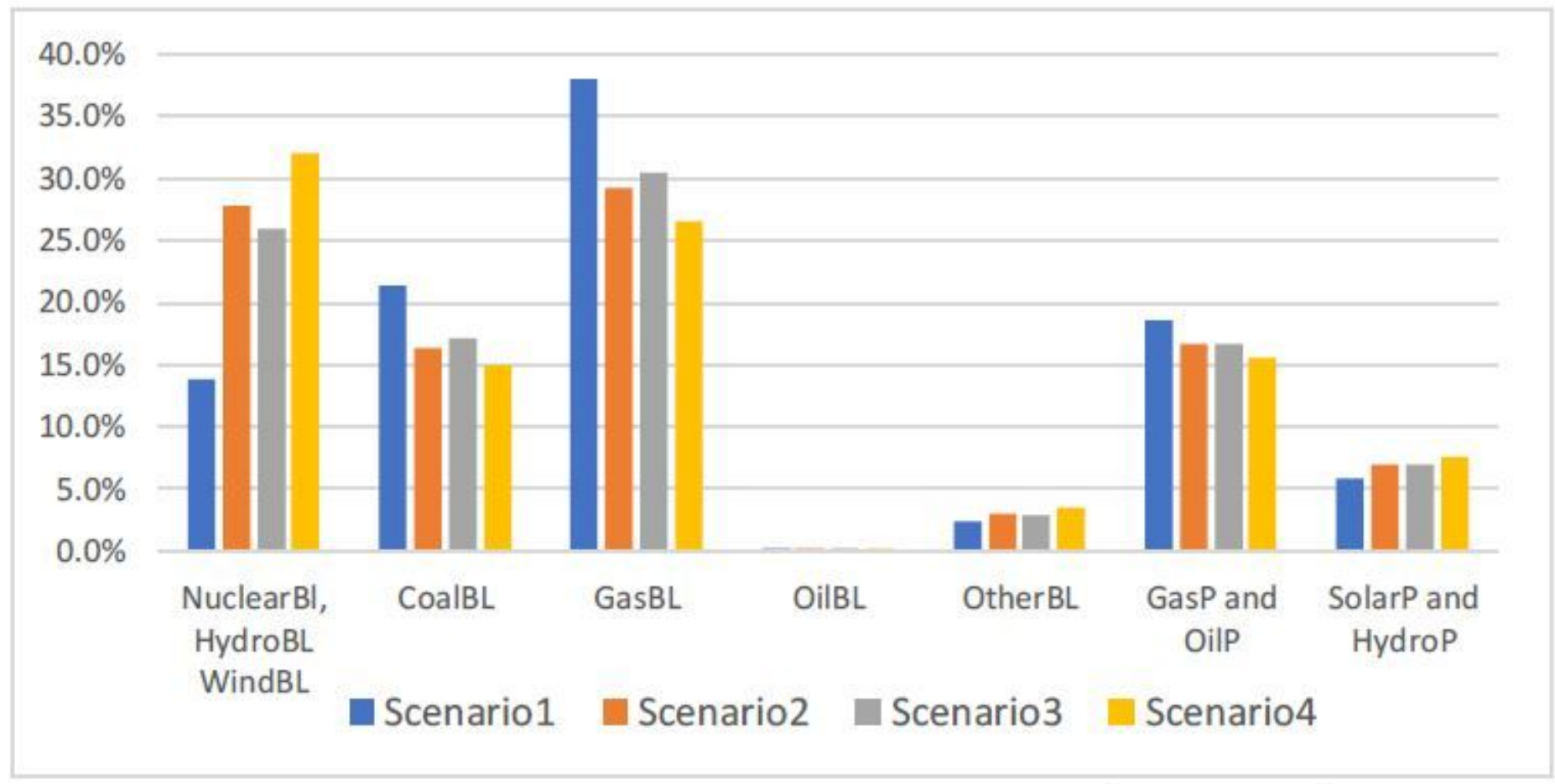

\section{Figure 7}

Power supply configuration in 2030 (percentage) Source: the authors.

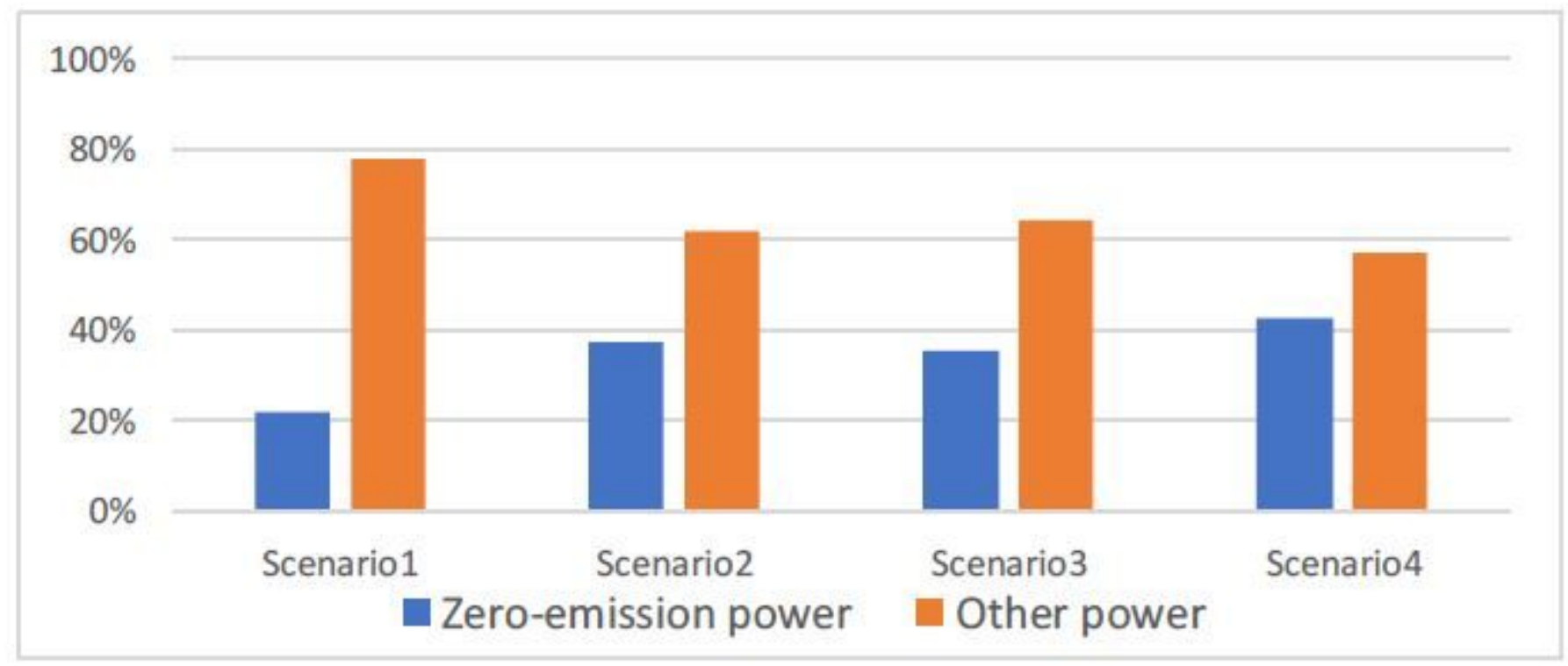

Figure 8

Power supply configuration in 2030: Zero-emission power and other power (percentage) Source: the authors 


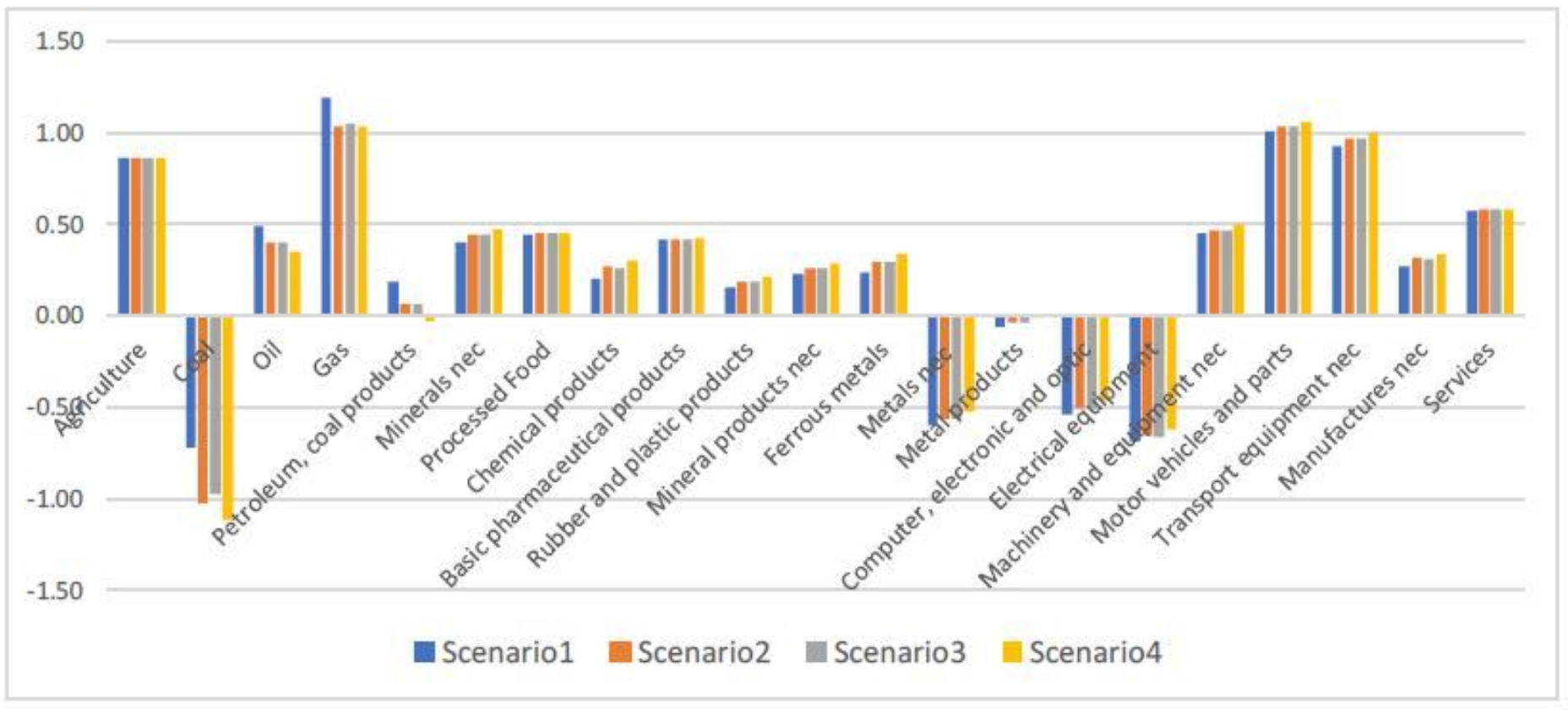

\section{Figure 9}

Impacts on Japan's industrial output: annual growth rate of non-power sectors from 2026 to 2030 (percentage) Source: the authors.

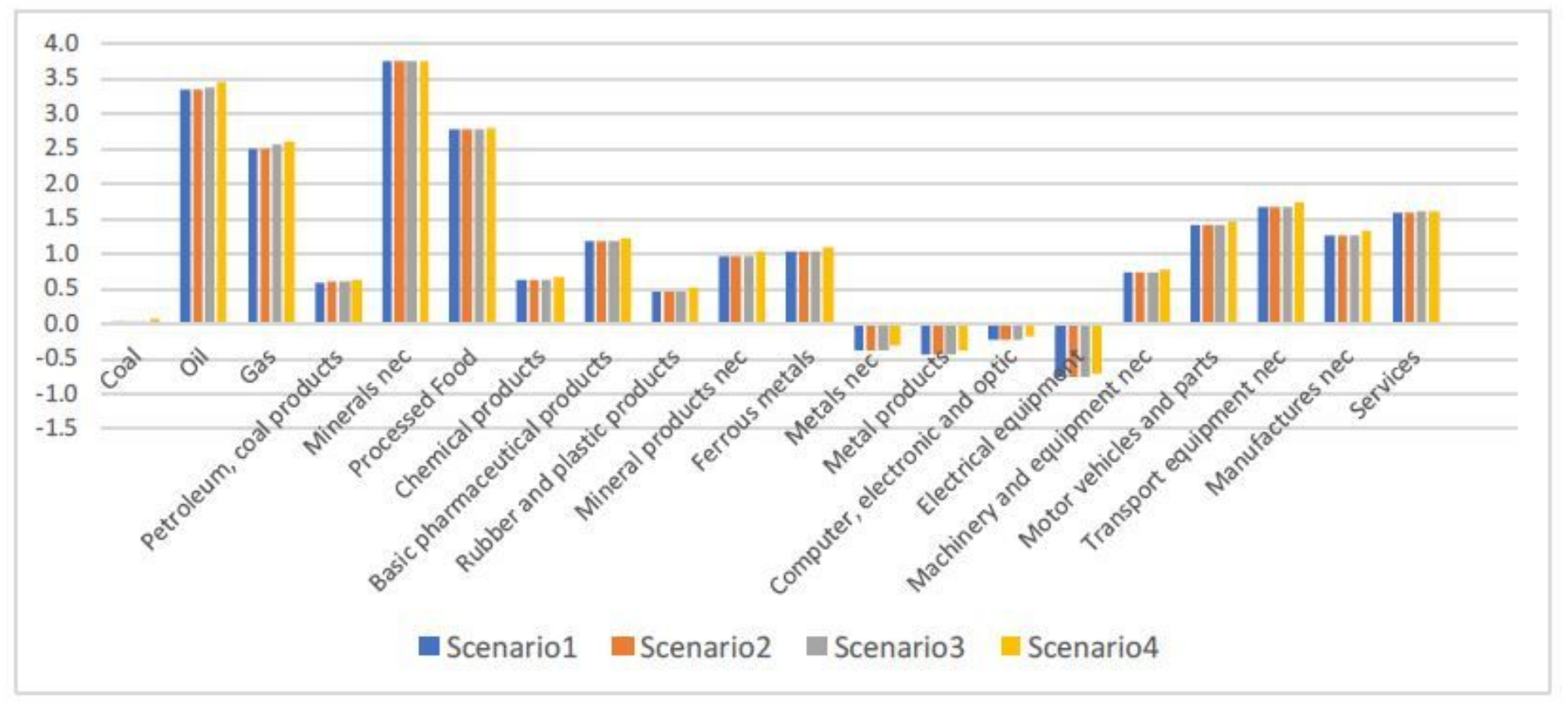

\section{Figure 10}

Impacts on Japan's exports by commodity: annual growth rate from 2026 to 2030 (percentage) Source: the authors. 


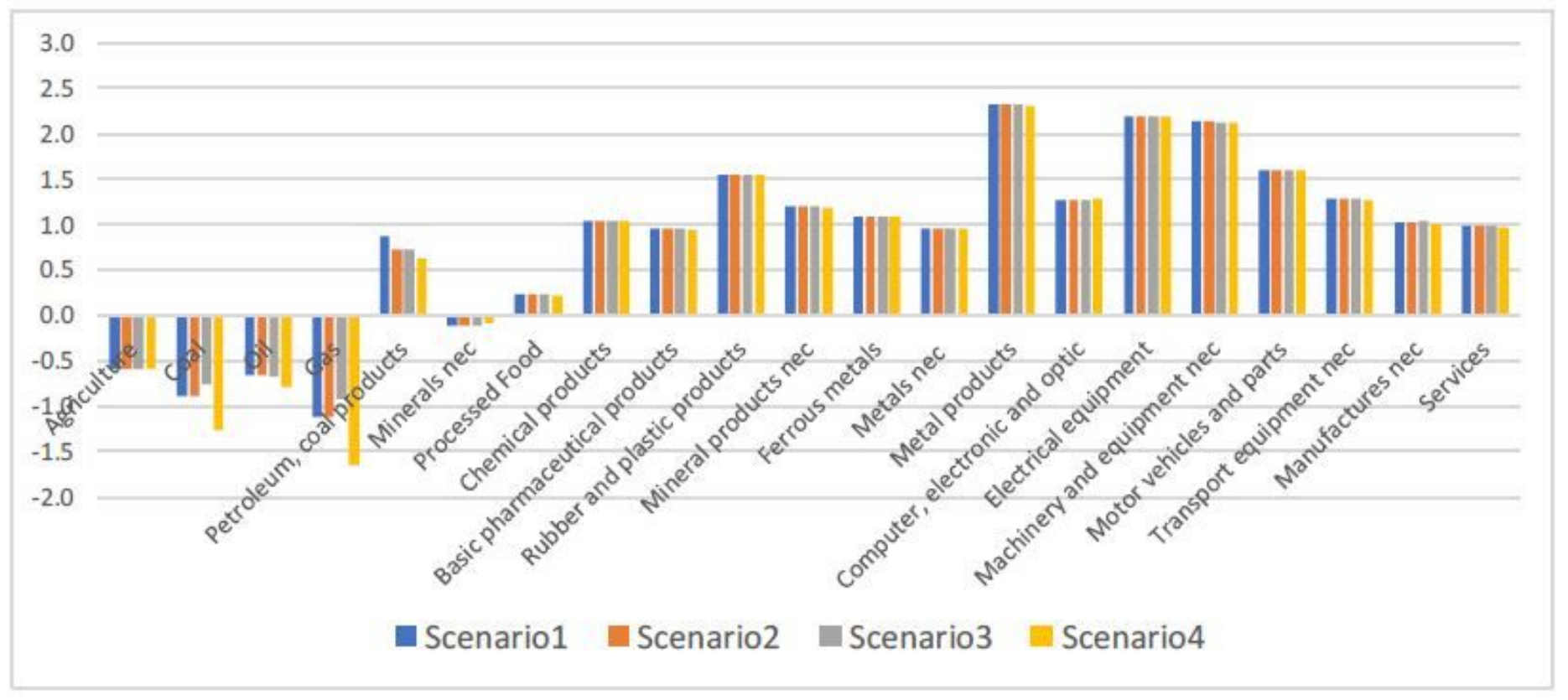

\section{Figure 11}

Impacts on Japan's imports by commodity: annual growth rate of non-power sectors from 2026 to 2030 (percentage) Source: Authors. 